\title{
One-year Outcome of Different Unprotected Left Main Percutaneous Coronary Interventions Techniques in Acute Coronary Syndromes
}

\author{
Amr Elhadidy (D), Mohamed AliD, Mahmoud Adel Gawish (D), Ayman Moharram (D), Khaled Taema*(D) \\ Department of Critical Care Medicine, Cairo University, Cairo, Egypt
}

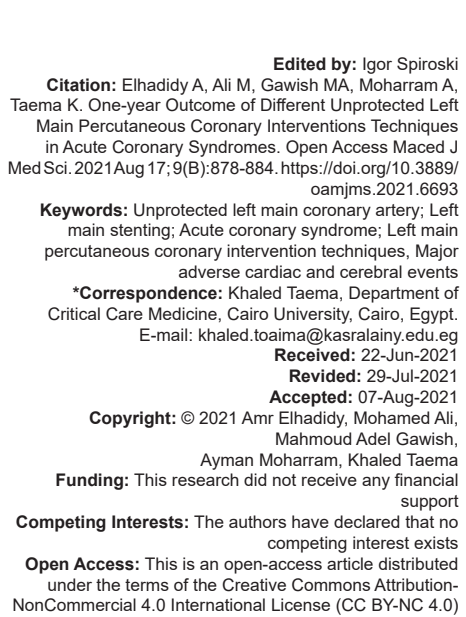

\section{Introduction}

About $5-10 \%$ of patients undergoing coronary angiography were shown to have left main coronary artery (LMCA) [1], [2]. Those represent the highest risk lesion subset and are associated with poor clinical outcomes coronary artery disease.

Early clinical trials showed that coronary artery bypass grafting (CABG) has better outcomes when compared to medical therapy in the treatment of LMCA disease, and accordingly, CABG was considered as the standard of care for the management of this subset of patients for a long time [3], [4].

In the later years, there were great advances in the medical device technology and percutaneous coronary intervention $(\mathrm{PCl})$ techniques. $\mathrm{PCls}$ became more popular with better outcomes due to these factors together with the advances in the adjunctive medical therapy and personal experiences [5], [6].

Despite that the short-term outcomes for LMCA stenting are well evaluated, its long-term trends in different patient subsets and with different techniques still need further elaboration. This may be important for helping clinical decision-making and is important for achieving better outcomes with LMCA disease management.

We intended in this study to evaluate the impact of the different techniques of unprotected LMCA (ULMCA) stenting on the clinical outcomes of acute coronary syndrome (ACS) patients.

\section{Patients and Methods}

The study protocol was approved by the Institutional Review Board at Cairo University and has been conducted in accordance with the principles set forth in the Helsinki Declaration. Informed consent was obtained from patients or first degree relative.

We included all adult patients admitted with ACS and left main (LM) arterial disease subjected to unprotected LM coronary intervention during the period from September 2018 to January 2020 in our multicenter observational prospective cohort study. We excluded from 
the study patients with age younger than 18 years and older than 75 years, patients with conditions that interfere with LM coronary intervention, patients who refused to be included in study, and those with previous CABG.

Following their admission, patients were subjected to detailed medical history, clinical examination, standard 12-lead ECG, routine laboratory investigations, and echocardiography. Cardiac catheterization and unprotected LM PCI were then done.

Angiographic assessment included evaluation of Syntax-II score, EURO-II score, and TIMI flow grading. The primary outcome of interest was the incidence of major adverse cardiac and cerebral events (MACCE) at 1 year follow-up. MACCE is defined as the composite of death, ACSs, target vessel revascularization (TVR), heart failure requiring hospitalization, and acute cerebrovascular event.

The secondary outcomes studied included contrast-induced nephropathy represented by the development acute kidney injury (AKI), defined by the increase of serum creatinine by $\geq 0.3 \mathrm{mg} / \mathrm{dl}$ within $72 \mathrm{~h}$ or increase of serum creatinine by 1.5 -fold of baseline within 1 week [7]. Other secondary outcomes included 1 year mortality and need for CABG post-PCI.

\section{Statistical analysis}

Data were initially evaluated for normality using Shapiro-Wilk test and z-value of skewness and kurtosis. Data with z-value of skewness and kurtosis between -1.96 and +1.96 [8] and Shapiro-Wilk test with $p>0.05$ [9], [10] are considered as normally distributed. Our continuous variables were non-normally distributed and were accordingly, expressed as median $\left(25^{\text {th }}-75^{\text {th }}\right)$ percentiles (Median $\left[Q_{1}-Q_{3}\right]$ ). Categorical variables were expressed as frequency and proportion. We used non-parametric test (Mann-Whitney U-test) to compare groups as regard quantitative variables and Chi-square test $\left(\chi^{2}\right)$ to compare groups regarding qualitative data. Exact test was used if the expected frequency is $<5$. Results were considered statistically significant if $p \leq 0.05$. Data collection, coding, and analysis were done using the Statistical Package for the Social Sciences (SPSS version 22).

\section{Results}

We initially recruited 78 patients with ACS and LM disease in the study. Thirteen patients were subsequently excluded due to lesions considered not suitable for $\mathrm{PCl}$ according to the operator's opinion (10 patients) and withdrawal of consent (three patients). The remaining 65 patients represented our study population. The baseline demographic, clinical, and angiographic data are shown in Table 1.
Table 1: The baseline demographic, clinical, and angiographic data

\begin{tabular}{|c|c|}
\hline Variable & Result \\
\hline Age (median $\left[Q_{1}-Q_{3}\right]$ ) years old & $63(53-70)$ \\
\hline Male gender $(\mathrm{n}[\%])$ & $46(70.8)$ \\
\hline \multicolumn{2}{|l|}{ Type of ACS ( $[\%]$ ) } \\
\hline UA & $39(60)$ \\
\hline NSTEMI & $12(18.5)$ \\
\hline STEMI & $1421.5)$ \\
\hline \multicolumn{2}{|l|}{ Diseased LM segments ( $\mathrm{n}[\%]$ ) } \\
\hline Aorto-ostial & $8(12.3)$ \\
\hline Mid-segment & $3(4.6)$ \\
\hline Distal segment & $37(56.9)$ \\
\hline Combined segments & $17(26.2)$ \\
\hline Isolated LM (n [\%]) & $11(16.9)$ \\
\hline Syntax score (median $\left[Q_{1}-Q_{3}\right]$ ) & $28(20-35)$ \\
\hline EUROSCORE (median $\left[Q_{1}-Q_{3}\right]$ ) & $4.80(1.79-14.15)$ \\
\hline \multicolumn{2}{|l|}{ Medina classification (n [\%]) } \\
\hline 1.1 .1 & $24(36.9)$ \\
\hline 1.1 .0 & $24(36.9)$ \\
\hline 1.0 .1 & $4(6.2)$ \\
\hline \multicolumn{2}{|c|}{ Angulation between LAD and LCX ( $\mathrm{n}[\%])$} \\
\hline$<70$ & $31(47.7)$ \\
\hline$>70$ & $34(52.3)$ \\
\hline \multicolumn{2}{|l|}{ Used technique (n [\%]) } \\
\hline 1-stent technique & $29(54.7)$ \\
\hline \multicolumn{2}{|l|}{ Planned 2-stent technique } \\
\hline TAP & $6(11.3)$ \\
\hline Culotte & $4(7.5)$ \\
\hline Mini-crush & $6(11.3)$ \\
\hline DK crush & $8(12.3)$ \\
\hline \multicolumn{2}{|l|}{ DES used (n [\%]) } \\
\hline Everolimus-eluting stent & $28(43.1)$ \\
\hline Sirolimus-eluting stent & $29(44.6)$ \\
\hline Biolimus-eluting stent & $6(9.2)$ \\
\hline Paclitaxel-eluting stent & $1(1.5)$ \\
\hline Zotarolimus-eluting stent & $1(1.5)$ \\
\hline \multicolumn{2}{|l|}{ Adjunctive techniques (n [\%]) } \\
\hline Side branch rewiring & $39(60)$ \\
\hline Final kissing inflation & $39(60)$ \\
\hline Proximal optimization technique & $32(49.2)$ \\
\hline Stent deployment using IVUS & $16(24.6)$ \\
\hline \multicolumn{2}{|l|}{ Procedural complication (n [\%]) } \\
\hline Dissection & $3(4.6)$ \\
\hline Acute stent thrombosis & $9(13.8)$ \\
\hline Distal embolization & $12(18.5)$ \\
\hline Side branch loss & $2(3.1)$ \\
\hline
\end{tabular}

The primary outcome of our study was the 1-year MACCE including the composite of death, ACSs, TVR, heart failure requiring hospitalization, and acute cerebrovascular event. The incidence of major adverse cardiovascular and cerebrovascular events within the $1^{\text {st }}$ year after LM stenting in our study was $63.1 \%$ (Figure 1).

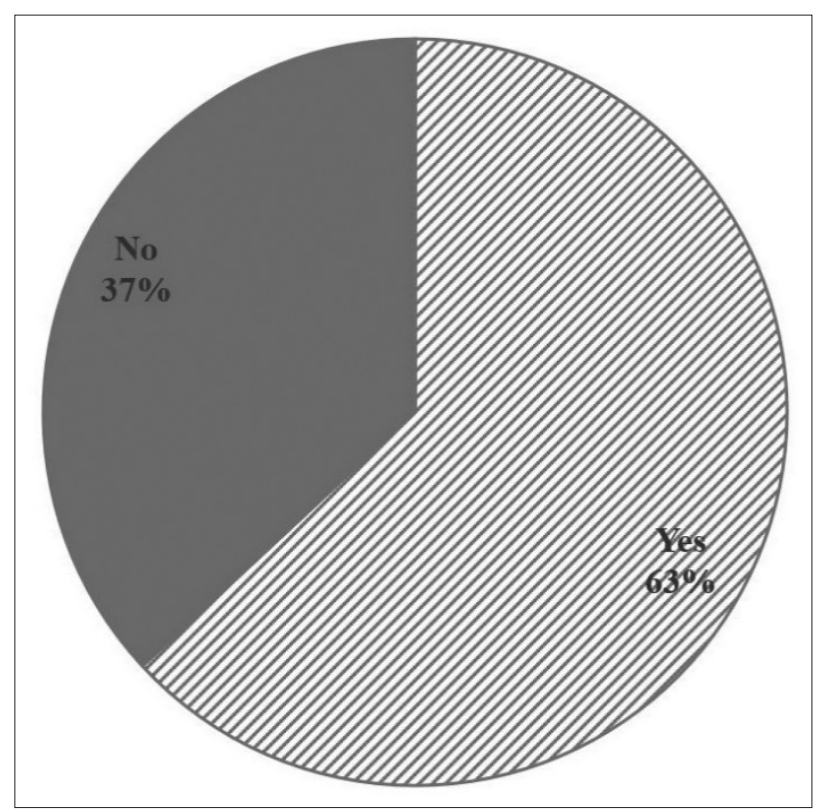

Figure 1: Incidence of 1-year major adverse cardiac and cerebral events 
Seven patients died within 1 year of the procedure with 1-year mortality rate of $10.8 \%$. CABG within 1 year of LM stenting was done in 4 patients (6.2\%). AKI occurred in 20 patients (30.8\%) (Figure 2).

The wide distal bifurcation angle between the left anterior descending (LAD) and left circumflex (LCX) $\left(>70^{\circ}\right)$ was associated with significantly lower 1-year MACCE rate. The incidence of 1-year MACCE was $46.2 \%$ when the angle was $>70^{\circ}$ compared to $81.5 \%$ when it was $<70(p=0.008)$. The wide angle was also associated with $0 \% 1$-year mortality compared to $18.5 \%$ for narrow angle, a difference which is statistically significant $(p=0.03)$ (Figure 3).

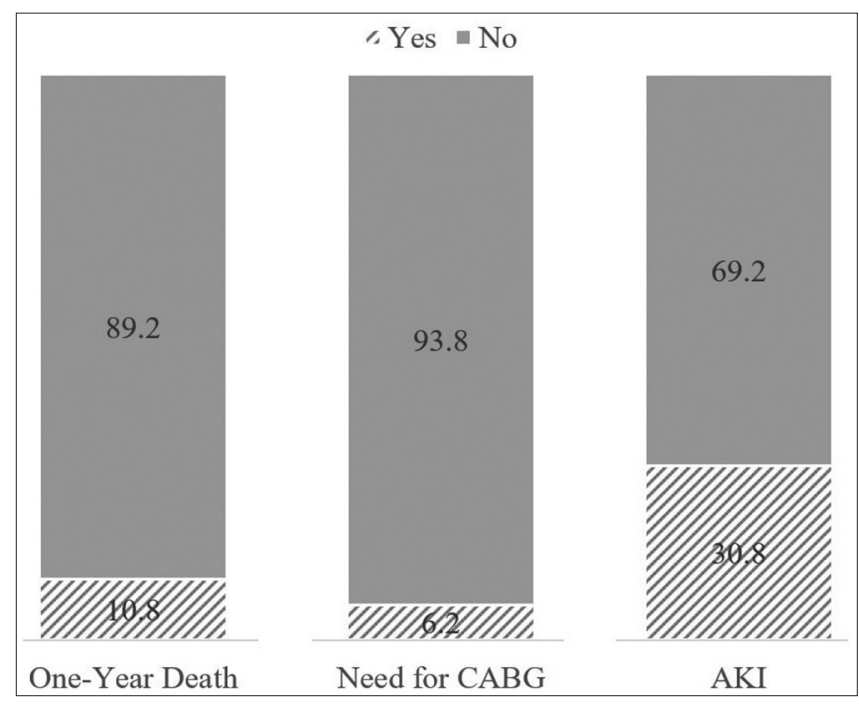

Figure 2: Incidence of 1-year death, need for coronary artery bypass graft, and acute kidney injury

The syntax score did not significantly affect the primary outcome of 1-year MACCE. It was 30 (21-36) in those who developed MACCE at 1 year compared to 25 (20-32) in those who did not develop MACCE $(p=0.12)$. It was even not significant predictor of any of the secondary outcomes (Figure 4).

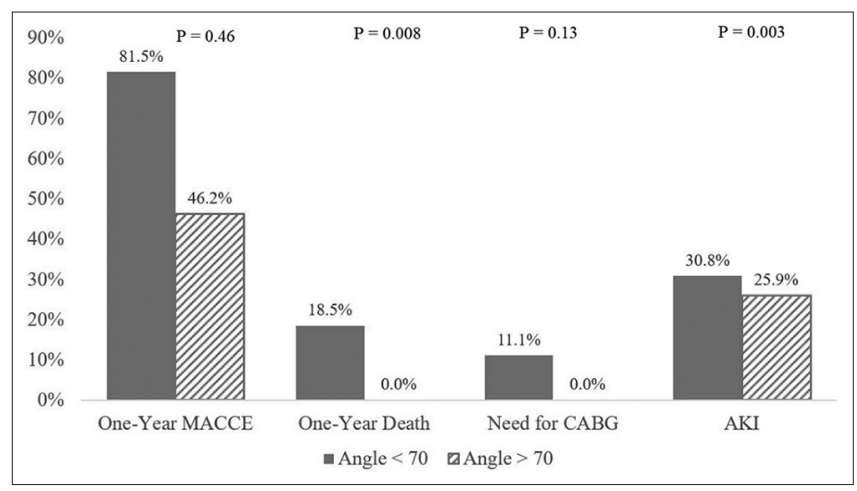

Figure 3: The relation between angulation and outcomes

Twenty-nine of our patients had 1-stent technique while 24 had planned 2-stent technique. Eighteen out of 29 patients who had 1-stent technique (62.1\%) developed MACCE at 1-year follow-up and similarly, 16 out of 24 who had 2 -stent technique $(66.7 \%)$ had 1-year MACCE $(p=0.48)$. Similarly, the use of whether 1-stent or 2-stent techniques did not affect the secondary outcomes. The incidence of need for CABG, $\mathrm{AKI}$, and 1 -year death was $6.9 \%, 31 \%$, and $13.8 \%$ in the 1 -stent technique group compared to $4.2 \%, 25 \%$, and $4.2 \%$ ( $p=0.57,0.43$, and 0.24 respectively).

Within patients with planned 2-stent technique, none of the used technique had a significant effect of any of the outcome parameters. The use of TAP was associated with $66.7 \%$ 1-year MACCE compared to $75 \%, 83.3 \%$, and $50 \%$ for culotte, mini-crush, and DK crush techniques, respectively $(p=0.6)$.

Within the patients with planned 2-stent technique, we compared the DK crush technique with the composite of other techniques together. The choice of either was not associated with a significant difference in outcomes. The DK crush group had and incidence of 1 -year MACCE of $50 \%$ compared to $75 \%$ in the non-DK crush group ( $p=0.22)$. The need for CABG, AKI, and 1 -year death occurred in $12.5 \%, 25 \%$, and $0 \%$ of DK crush group compared to $0 \%, 25 \%$, and $6.3 \%$ in non-DK crush group ( $p=0.33,0.7$, and 0.7 , respectively).

The use of final kissing inflation (FKI) and proximal optimization technique (POT) was associated with significantly lower incidence of 1-year MACCE. When FKI was used, the 1-year MACCE was $35.7 \%$ compared to $74.4 \%$ when it was not used ( $p=0.013$ ). When POT was used, the 1-year MACCE was $47.6 \%$ compared to $75 \%$ when it was not used $(p=0.041)$.

We used intravascular ultrasound (IVUS) to guide stent deployment in 16 patients, 8 of them (50\%) developed MACCE at 1 year while the other $50 \%$ did not while 33 of 49 patients who did not use IVUS (67.3\%) developed MACCE $(p=0.21)$.

\section{Discussion}

CABG surgery continued to be the firstline therapy for ULMCA disease for several years. Subsequent advances achieved in medical technology including the revolution of developing the drug-eluting stents (DESs), together with the development in operator experiences and the advances in adjunctive pharmacotherapies rendered $\mathrm{PCl}$ a feasible alternative for ULMCA stenosis management. In 2008, Buszman et al. published one of the earliest studies that compared UPLMT PCl and CABG [11]. They showed a lower risk of 30-day MACCE events after $\mathrm{PCl}$ compared with CABG. The PCl group also showed a significant improvement in the left ventricular ejection fraction after 12 months. Both groups demonstrated similar improvement in angina and good long-term functional capacity on exercise stress testing [11]. This study, however, did not show the impact of different 


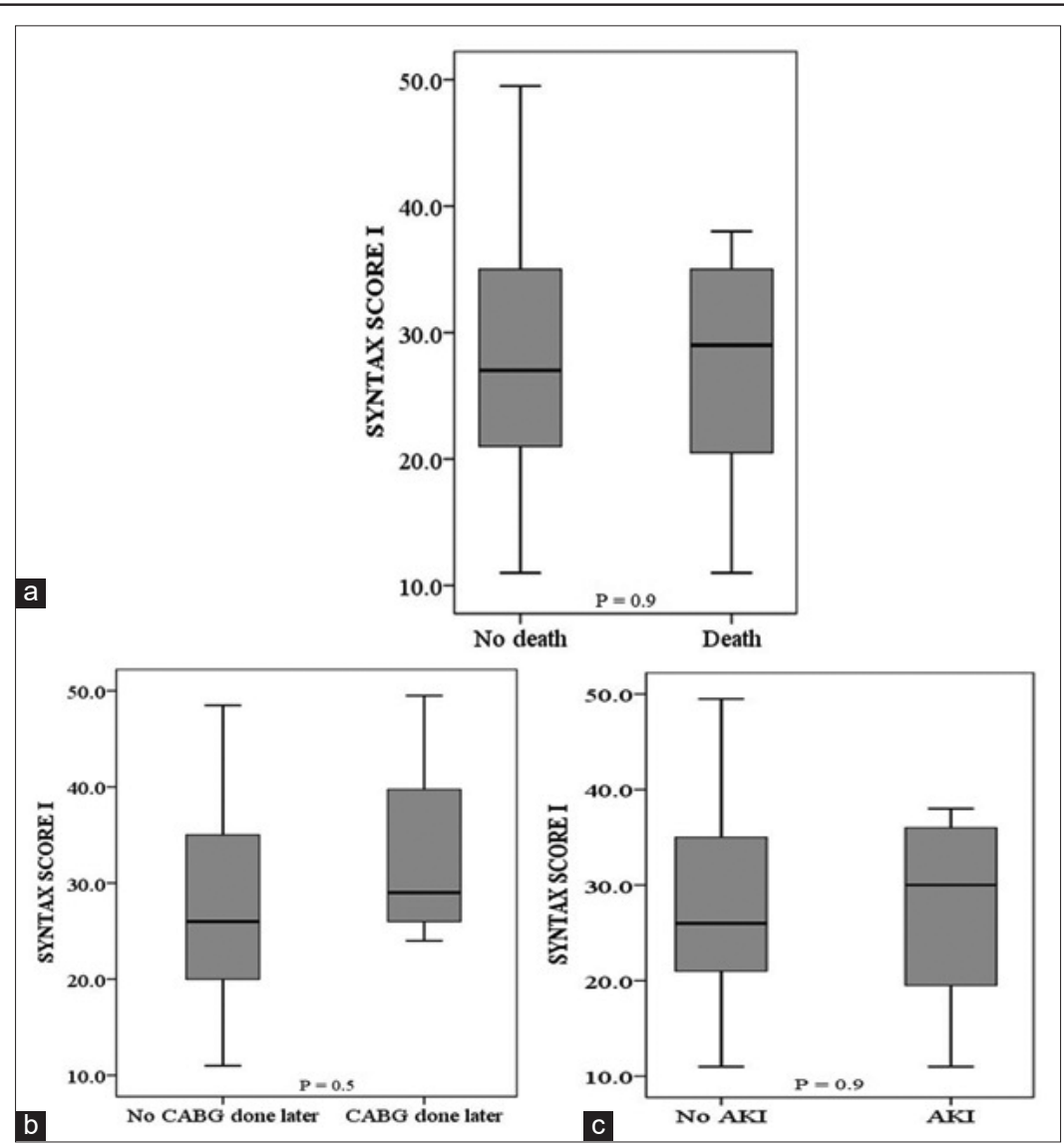

Figure 4: The effect of the Syntax score on the clinical outcomes, (a) 1 year death, (b) coronary artery bypass graft done later, and (c) acute kidney injury

techniques of $\mathrm{PCl}$ as they standardized the technique using provisional stenting and FKIs.

Even with the consideration of the great advances in $\mathrm{PCl}$ techniques and operator experience, UPLMCA bifurcation $\mathrm{PCl}$ is still challenging. Our study was a multicenter observational prospective study conducted on patients presented with ACS due to LMCA disease to assess different techniques of $\mathrm{PCl}$ in ULMCA and their impact on different outcomes including MACCE after 1 year as a primary outcome. The secondary outcomes of our study were AKI, need for CABG, and 1-year mortality within 1 year after the procedure.

We found that the distal bifurcation angle between $L A D$ and $L C X<0^{\circ}$, non-use of $F K I$, and nonuse of POTs is significantly associated with higher incidence of 1-year MACCE. None of the other studied variables were seen to be predictors for the occurrence of 1-year MACCE.

Amemiya et al. found also that the target lesion revascularization (TLR) is higher with lower bifurcation angle [12]. At 1-year, free survival rate from MACE was $66.7 \%$ in low bifurcation angle group compared to $85.7 \%$ and $91.1 \%$ in middle and high bifurcation angles, respectively [12]. It should be emphasized that they considered the proximal bifurcation angle between LM and $L A D$ rather than the distal bifurcation angle that we used. They also did not elucidate relationship between angulation and MI or hospital death. The SYNTAX trial showed that the angle between the LAD and LCX is not a significant predictor for clinical results [13]. A wide angle between LM and LAD was also seen to be associated with a reduced event rate after stenting because of a less frequent TLR [12]. In the subset of patients with culotte and crush techniques, a wide angle between the LAD and the LCX was seen to significantly predict worse outcome [14], [15], [16]. However, there was an evidence of lower MACCE rate after DK crush technique when the bifurcation angle was $>70^{\circ}$ compared with the culotte stenting technique [17]. Stent implantation in the main vessel may affect the bifurcation angle. Some authors showed that stent implantation increased the angle between main vessel and the main branch which was explained by the straightening of the main vessel caused by the stent scaffold [18]. These findings support the notion that the main vessel angle might affect the clinical outcome after single-stent strategy from LM to LAD in LM bifurcation lesions.

Several mechanisms could explain the effect of angulation on the clinical outcomes. The bifurcation angle is considered as one of the contributing factors of stent fracture [19]. The mechanical stress applied by extrinsic compression may cause stent fracture which may play a role in stent restenosis [20]. The maximal angulation in the target lesion might have a role in this stent fracture [21]. The mechanical constraints might cause stent fractures which may be microfracture which 
is not visible by angiography. The angulation of the bifurcation causes some form of stent bending which also plays a role in the impact of the angulation on the clinical outcome [22].

Many of the studies that evaluated the different bifurcation techniques on the clinical outcomes compared the 1-stent versus planned 2-stent techniques. We did not elucidate any significant impact from using one-stent versus two-stent techniques on either 1-year MACCE or other secondary outcomes. Despite that Kandzari et al. found a more favorable clinical outcomes at 3 years with the use of provisional stent technique, these favorable results were not present at 1 month follow-up [23]. This 3-year favorable outcome was also ameliorated if both distal LM major side branches had an ostial diameter stenosis $\geq 50 \%$ [23].

The use of 1-stent technique was not associated with favorable outcome compared to 2-stent technique in our study. However, Cho et al. reported a better 3-year MACCE, TLR, and myocardial infarction (MI) with 1-stent strategy [24]. In sub-analysis of the study data, they showed that these clinical benefits were confined to the early generation DES with similar clinical outcomes including 3-year MACE, MI, and TLR for both 1-stent and 2-stent strategy groups for patients who had the new generation DES used [24]. The improved outcome with the new generations of DES represents not only an improved stent profile but also development of $\mathrm{PCl}$ technique (e.g. POT and final kissing balloon inflation) and operator experience that may have contributed to improvement in clinical outcomes after using the 2-stent strategy. The results of Song et al. [16] suggested that the use of new-generation DES, non-compliant balloon, or final kissing balloon was associated with better long-term outcomes in patients with bifurcation lesions who were treated by a 2-stent strategy. POT can optimize the stent diameter to LMCA diameter, in addition to correcting stent mal-apposition and reducing ellipticity of the stented segment [25]. The use of FKI was seen by many previous studies to improve the clinical outcome in 2-stent techniques [26], [27]. Despite that the FKI could cause a change in the stent shape, other studies [28], [29] showed that it could prevent stent distortion caused by balloon dilation through the side branch. In our study, FKI was associated by 35.7\% 1-year MACCE compared to $74.4 \%$ if FKI was not used and POT was associated by $47.6 \% 1$-year MACCE compared to $75 \%$ when it was not used; these differences were seen to be statistically significant. Finet et al. [25] compared six different optimization sequences for bifurcation provisional stenting. The MACE rate did not improve with the use of $\mathrm{KBI}$ in this study. They considered that the proximal stent deformation might increase stent restenosis rate and subsequently, TLR. They concluded that the re-POT improved the final angiographic results by maintaining circular vessel shape and avoiding side branch obstruction. These experimental findings confirm the beneficial effect of using re-POT as a final step of bifurcation $\mathrm{PCl}$.

Planned 2-stent technique might be mandatory if both side branches are significantly diseased. Many studies, like ours, included different techniques within the 2-stent groups as the DK crush and culotte stenting [30], [31], [32], [33]. In patients with true distal LM bifurcation disease, comparing the DK crush technique with either culotte 2-stent technique [30] or a provisional 1-stent strategy [31] revealed better outcomes in favor of DK crush technique. During a 5 -year evaluation of the different bifurcation techniques, the 2-stent technique, apart from DK crush, was a significant predictor of 5-year MACCE while the DK crush was associated with better clinical outcome [32]. Among patients treated with the 2-stent technique, Palmerini et al. showed contradictory results showing that the different treatment approaches ( $T$ stenting, $V$ stenting, and crush stenting) provided similar clinical outcomes [33]. Similarly, the use of the different techniques in our study was not associated by any significant advantages in terms of clinical outcomes.

The use of IVUS guidance during LM PCI did not affect any of the study outcomes in our study. Despite that many studies revealed a favorable outcome with lower incidence of MACE and death with the use of IVUS guided in comparison to angiography-guided stent implantation [34], [35], some of these studies [35] revealed more complex lesions and more comorbidities in the angiography-guided stent implantation group. These differences may affect the study results. We used IVUS to guide the stent deployment only in 16 patients. This small sample size made the conclusion regarding its efficacy to be questioned.

The degree of lesion complexity guided by syntax score did not affect any of the study outcomes. Many other studies showed that higher syntax scores are independent predictor for incidence of MACCE [36]. This discrepancy may be explained by different centers, different operators, small sample size, and relatively short period of follow-up.

Our study is limited by the small sample size. The choice of the procedure technique was left to the operator discretion with no randomization of the different techniques. This may represent a source of bias. The use of adjunctive devices as the IVUS included very limited number of patients.

\section{Conclusions}

We concluded in this study that the non-use of FKI nor POT together with the lower angulation between LM and LAD could predict worse clinical outcome at 1-year in unprotected $\mathrm{LM} \mathrm{PCl}$ which is a reliable therapeutic strategy for LM diseases treatment in ACSs patients. 


\section{References}

1. Lipton MJ. Disease of the left main coronary artery. Chest. 1979;76(6):616-8. https://doi.org/10.1378/chest.76.6.616 PMid:509997

2. Stone $\mathrm{P}$, Goldschlager N. Left main coronary artery disease: Review and appraisal. Cardiovasc Med. 1979;4:165-77.

3. Yusuf S, Zucker D, Passamani E, Peduzzi P, Takaro T, Fisher LD, et al. Effect of coronary artery bypass graft surgery on survival: Overview of 10 -year results from randomised trials by the coronary artery bypass graft surgery trialists collaboration. Lancet. 1994;344(8922):563-70. https://doi.org/10.1016/ s0140-6736(94)91963-1

PMid:7914958

4. Caracciolo EA, Davis KB, Sopko G, Kaiser GC, Corley SD, Schaff $\mathrm{H}$, et al. Comparison of surgical and medical group survival in patients with left main equivalent coronary artery disease. Circulation. 1995;91(9):2335-44. https://doi. org/10.1161/01.cir.91.9.2335

PMid:7729019

5. Park SJ, Park DW. Percutaneous coronary intervention with stent implantation versus coronary artery bypass surgery for treatment of left main coronary artery disease is it time to change guidelines? Circ Cardiovasc Interv. 2009;2(1):59-68. https://doi.org/10.1161/circinterventions.108.831701

PMid:20031694

6. Harskamp RE, Park DW. Stenting versus surgery for significant left main disease. Curr Cardiol Rep. 2015;17(4):18. https://doi. org/10.1007/s11886-015-0574-z

PMid:25702314

7. McCullough PA, Wolyn R, Rocher LL, Levin RN, O'Neill WW. Acute renal failure after coronary intervention: Incidence, risk factors, and relationship to mortality. Am J Med. 1997;103(5):36875. https://doi.org/10.1016/s0002-9343(97)00150-2 PMid:9375704

8. Doane DP, Seward LE. Measuring skewness: A forgotten statistic. J Stat Educ. 2011;19(2):1-18.

9. Shapiro SS, Wilk MB. An analysis of variance test for normality (complete samples). Biometrika. 1965;52(3-4):591-611. https:// doi.org/10.1093/biomet/52.3-4.591

10. Razali NM, Wah YB. Power comparisons of shapiro-wilk, kolmogorov-smirnov, lilliefors and anderson-darling tests. J Stat Model Anal. 2011;22:21-33.

11. Buszman PE, Kiesz SR, Bochenek A, Peszek-Przybyla E, Szkrobka I, Debinski M, et al. Acute and late outcomes of unprotected left main stenting in comparison with surgical revascularization. J Am Coll Cardiol. 2008;51(5):538-45. https:// doi.org/10.1016/j.jacc.2007.09.054

PMid:18237682

12. Amemiya K, Domei T, Iwabuchi M, Shirai S, Ando K, Goya M, et al. Impact of the bifurcation angle on major cardiac events after cross-over single stent strategy in unprotected left main bifurcation lesions: 3-Dimensional quantitative coronary angiographic analysis. Am J Cardiovasc Dis. 2014;4(4):168-76. https://doi.org/10.1016/s0735-1097(12)61526-5

PMid:25628958

13. Girasis C, Farooq V, Diletti R, Muramatsu T, Bourantas CV, Onuma $\mathrm{Y}$, et al. Impact of 3-dimensional bifurcation angle on 5-year outcome of patients after percutaneous coronary intervention for left main coronary artery disease: A substudy of the SYNTAX trial (synergy between percutaneous coronary intervention with taxus and cardiac surgery). JACC CardiovasC Interv. 2013;6(12):1250-60. https://doi.org/10.1016/j. jcin.2013.08.009

\section{PMid:24355115}

14. Adriaenssens T, Byrne RA, Dibra A, lijima R, Mehilli J, Bruskina $\mathrm{O}$, et al. Culotte stenting technique in coronary bifurcation disease: Angiographic follow-up using dedicated quantitative coronary angiographic analysis and 12-month clinical outcomes. Eur Heart J. 2008;29(23):2868-76. https:// doi.org/10.1093/eurheartj/ehn512

PMid: 19001472

15. Dzavik V, Kharbanda R, Ivanov J, Ing DJ, Bui S, Mackie K, et al. Predictors of long-term outcome after crush stenting of coronary bifurcation lesions: Importance of the bifurcation angle. Am Heart J. 2006;152(4):762-9. https://doi.org/10.1016/j. ahj.2006.04.033

PMid:16996856

16. Song PS, Bin SY, Lee JM, Hahn JY, Choi SH, Choi JH, et al. Major predictors of long-term clinical outcomes after percutaneous coronary intervention for coronary bifurcation lesions with 2-stent strategy: Patient-level analysis of the korean bifurcation pooled cohorts. JACC Cardiovasc Interv. 2016;9(18):1879-86. https://doi.org/10.1016/j.jacc.2016.09.457

PMid:27592016

17. Chen SL, Xu B, Han YL, Sheiban I, Zhang JJ, Ye F, et al. Comparison of double kissing crush versus culotte stenting for unprotected distal left main bifurcation lesions: Results from a multicenter, randomized, prospective DKCRUSH-III study. J Am Coll Cardiol. 2013;61(14):1482-8. https://doi.org/10.1016/j. jacc.2013.01.023

PMid:23490040

18. Vassilev D, Gil RJ. Relative dependence of diameters of branches in coronary bifurcations after stent implantation in main vessel-importance of carina position. Kardiol Pol. 2008;66(4):371-8; discussion 379.

PMid: 18473265

19. Rathore S, Ball T, Nakano M, Kaplan A, Virmani R, Foerst J. Circumferential strut fracture as a mechanism of "crush" bifurcation restenosis. Am J Cardiol. 2013;111(5):770-3. https:// doi.org/10.1016/j.amjcard.2012.11.030

PMid:23291090

20. Surmely JF, Kinoshita Y, Dash D, Matsubara T, Terashima M, Ehara $M$, et al. Stent strut fracture-induced restenosis in a bifurcation lesion treated with the crush stenting technique. Circ J. 2006;70(7):936-8. https://doi.org/10.1253/circj.70.936 PMid:16799252

21. Ino $\mathrm{Y}$, Kubo $\mathrm{T}$, Kitabata $\mathrm{H}$, Shimamura $\mathrm{K}$, Shiono $\mathrm{Y}$, Orii $\mathrm{M}$, et al. Impact of hinge motion on in-stent restenosis after sirolimus-eluting stent implantation. Circ J. 2011;75(8):1878-84. https://doi.org/10.1253/circj.cj-10-1182

PMid:21628832

22. Ino $\mathrm{Y}$, Toyoda $\mathrm{Y}$, Tanaka A, Ishii S, Kusuyama $\mathrm{Y}$, Kubo T, et al. Predictors and prognosis of stent fracture after sirolimus-eluting stent implantation. Circ J. 2009;73(11):2036-41. https://doi. org/10.1253/circj.cj-09-0343

PMid:19713648

23. Kandzari DE, Gershlick AH, Serruys PW, Leon MB, Morice MC, Simonton CA, et al. Outcomes among patients undergoing distal left main percutaneous coronary intervention: Technique analysis from the EXCEL trial. Circ Cardiovasc Interv. 2018;11(10):e007007. https://doi.org/10.1161/ circinterventions.118.007007

PMid:30354633

24. Cho S, Kang TS, Kim JS, Hong SJ, Shin DH, Ahn CM, et al. Long-term clinical outcomes and optimal stent strategy in left main coronary bifurcation stenting. JACC Cardiovasc Interv. 2018;11(13):1247-58. https://doi.org/10.1016/j.jcin.2018.03.009 PMid:29976361 
25. Finet G, Derimay F, Motreff P, Guerin P, Pilet P, Ohayon J, et al. Comparative analysis of sequential proximal optimizing technique versus kissing balloon inflation technique in provisional bifurcation stenting: Fractal coronary bifurcation bench test. JACC Cardiovasc Interv. 2015;8(10):1308-17. https://doi.org/10.1016/j.jcin.2015.05.016 PMid:26315733

26. Kervinen K, Niemelä M, Romppanen H, Erglis A, Kumsars I, Maeng $\mathrm{M}$, et al. Clinical outcome after crush versus culotte stenting of coronary artery bifurcation lesions: The nordic stent technique study 36-month follow-up results. JACC Cardiovasc Interv. 2013;6(11):1160-5. https://doi.org/10.1016/j. jcin.2013.06.009

PMid:24262616

27. Ge L, Airoldi F, lakovou I, Cosgrave J, Michev I, Sangiorgi GM, et al. Clinical and angiographic outcome after implantation of drug-eluting stents in bifurcation lesions with the crush stent technique: Importance of final kissing balloon post-dilation. J Am Coll Cardiol. 2005;46(4):613-20. https://doi.org/10.1016/j. jacc.2005.05.032

PMid:16098424

28. Ormiston JA, Webster MW, Ruygrok PN, Stewart JT, White HD, Scott DS. Stent deformation following simulated side-branch dilatation: A comparison of five stent designs. Catheter Cardiovasc Interv. 1999;47(2):258-64. https://doi.org/10.1002/ (sici)1522-726x(199906)47:2<258:aid-ccd27>3.0.co;2-c PMid:10376516

29. Ormiston JA, Webster MW, El Jack S, Ruygrok PN, Stewart JT, Scott D, et al. Drug-eluting stents for coronary bifurcations: Bench testing of provisional side-branch strategies. Catheter Cardiovasc Interv. 2006;67(1):49-55. https://doi.org/10.1002/ ccd.20453 PMid: 16003787

30. Chen SL, Xu B, Han YL, Sheiban I, Zhang JJ, Ye F, et al Clinical outcome after DK crush versus culotte stenting of distal left main bifurcation lesions: The 3-year follow-up results of the DKCRUSH-III study. JACC Cardiovasc Interv. 2015;8(10):133542. https://doi.org/10.1016/j.jcin.2015.05.017

PMid:26315736
31. Chen SL, Zhang JJ, Han Y, Kan J, Chen L, Qiu C, et al Double kissing crush versus provisional stenting for left main distal bifurcation lesions: DKCRUSH-V randomized trial. J Am Coll Cardiol. 2017;70(21):2605-17. https://doi.org/10.1161/ circinterventions.116.004497

\section{PMid:29096915}

32. Chen SL, Zhang Y, Xu B, Ye F, Zhang J, Tian N, et al. Fiveyear clinical follow-up of unprotected left main bifurcation lesion stenting: One-stent versus two-stent techniques versus doublekissing crush technique. Eurolntervention. 2012;8(7):803-14 https://doi.org/10.4244/eijv8i7a123

PMid:23171801

33. Palmerini T, Marzocchi A, Tamburino C, Sheiban I, Margheri M, Vecchi G, et al. Impact of bifurcation technique on 2-year clinical outcomes in 773 patients with distal unprotected left main coronary artery stenosis treated with drug-eluting stents. Circ Cardiovasc Interv. 2008;1(3):185-92. https://doi.org/10.1161/ circinterventions.108.800631 PMid:20031677

34. Zhang Y, Farooq V, Garcia-Garcia HM, Bourantas CV, Tian N, Dong $\mathrm{S}$, et al. Comparison of intravascular ultrasound versus angiography-guided drug-eluting stent implantation: A metaanalysis of one randomised trial and ten observational studies involving 19, 619 patients. Eurolntervention. 2012;8(7):855-65. https://doi.org/10.4244/eijv8i7a129

PMid:23171805

35. Gao XF, Kan J, Zhang YJ, Zhang JJ, Tian NL, Ye F, et al Comparison of one-year clinical outcomes between intravascular ultrasound-guided versus angiography-guided implantation of drug-eluting stents for left main lesions: A single-center analysis of a 1, 016-patient cohort. Patient Prefer Adherence. 2014;8:1299-309. https://doi.org/10.2147/ppa.s65768 PMid:25278749

36. Alidoosti M, Safarian H, Shafiee A, Salarifar M, Poorhosseini H, Nematipour E. The SYNTAX score can predict major adverse cardiac events following percutaneous coronary intervention. Heart Views. 2014;15(4):99-105. https://doi. org/10.4103/1995-705x.151081

PMid:25774251 